\title{
Social support and emotional exhaustion among hospital nursing staff
}

\author{
M. ${ }^{\text {J J. Albar Marín* }}$ \\ M. García-Ramírez ${ }^{\star \star}$ \\ * Servicio Andaluz de Salud \\ ** Universidad de Sevilla \\ SPAIN
}

\begin{abstract}
The role of three sources of social support (family as kin, co-workers as insiders, and supervisors as outsiders) on the emotional exhaustion were analyzed in a sample of 210 nurses at a general hospital in Seville, a city in the south of Spain. They were given an adaptation of the Nursing Stress Scale, (Gray-Toff \& Anderson 1981), the Multidimensional Support Scale (Winefield, Winefield, Tiggemann 1992), previously adapted in a sample of nurses and the emotional exhaustion scale of the Spanish version of Maslach's Burnout Inventory (1997). After applying a hierarchical multiple regression analysis to the data, the results confirm the main effect of the three sources and the buffering effect in the case of outsiders and kin. It suggests the need to perform studies with wider samples, which allow the analysis of professionals' psychosocial characteristics and types of support, as well as demands in nursing job tasks.
\end{abstract}

\section{Social Support Sources and Emotional Exhaustion among Hospital Nursing Staff}

The hospital nursing staff (HNS) has been identified as one of the groups at risk of suffering emotional exhaustion, a preliminary stage of burnout syndrome, due to the nature, intensity and diversity of the stressors related to their job tasks (Leiter 1993, Maslach \& Leiter 1997, Maslach, Shaufeli \& Leiter 2001). It has been observed that social support prevents their appearance because a) it decreases the intensity of the stressors and b) it interacts with them, reducing their consequences (Maslach Shaufeli \& Leiter 2001). Nevertheless, gaps remain to be solved regarding the nature of these effects, especially the differences that may be produced depending on the source of the help. The aim of this study was to examine the role of the different social support sources in the prevention of emotional exhaustion among HNS. 


\section{Job Stress, Emotional Exhaustion and Social Support}

Studies carried out from the transactional perspective have highlighted that the job demands of HNS can increase the job stress and overwhelm personal coping resources and, consequently, unleash physical and emotional reactions. The nature of these job demands may be physical (e.g. work overload), emotional (e.g. continuous contact with suffering and death), and social (e.g. problems interacting with co-workers) (Gray-Toft \& Anderson 1981, Schaefer \& Moos 1993). As a consequence, both health and job performance become affected (Lazarus 1991).

Among the psychological reactions which take place as a consequence of the continuous exposure to this job stress is burnout syndrome, characterized by the development of the experience of finding oneself mentally fatigued, negative attitudes towards the people to whom their work is directed, and the idea of having failed professionally (Shaufeli et al. 1996). It is a process, initiated after continuously suffering the perception of inability to face job demands with the available resources, which leads to the development of emotional exhaustion (Leiter 1993, Maslach \& Leiter 1997). Afterwards, a process of depersonalization is triggered, characterized by the tendency to treat patients in a mechanical way, until finally, the professionals become less and less effective at achieving their objectives, develop feelings of incompetence and lessen their personal development (Cordes \& Dougherty 1993, Lee \& Asforth 1993). Emotional exhaustion is considered a dimension with high predictive value of the results of stress in the health of the active work population (Maslach, Shaufeli \& Leiter 2001).

Research has revealed the importance of social support in coping with job stress and preventing emotional exhaustion (Maslach, Shaufeli \& Leiter 2001). Social support is defined as the mesh of social relationships and transactions (i.e. emotional, cognitive, and behavioral) whose function is to complete the personal resources to allow adaptive coping in situations of need (Sarason \& Duck 2001). To analyze its role against job stress, the main and buffering effect hypotheses have been tested. The main effect postulates that social support enhances health and wellbeing irrespective of the person's stress level because it decreases the intensity of the experience of the stress (Eisenberger, Fasolo \& Davis-LaMastro 1990). The buffering effect establishes that social support interacts with job stress to reduce distress responses, in such a way that the relationship between job stress and distress is greater in individuals with low levels of support (Greenglass, Fiksenbaum \& Burke 1994).

Nonetheless, empirical evidence has not been able to find consistency in the results, so in some studies the main effect of support does not appear, while in others, the buffer effect (Chapell \& Novak 1992) and an opposite effect have even been observed, that is, high support levels exacerbate more than alleviate the effect of stress job, producing processes of personal weakening and loss of social status (Kauffmann \& Beehr 1986). These inconsistencies have been explained based on both conceptual and methodological problems, especially the consideration of support as a one-dimensional structure, which has prevented the analysis of the different role that 
the personal social network links play against job stress and its consequences.

\section{The Role of Social Support Sources}

Research on social support has observed that it is necessary to consider their source. It has become relevant to differentiate between a) kin, formed by your partner, parents and significant others, who are solid and effective ties in numerous situations; b) insiders, such as co-workers, who are ties relatively dependent on their role, but vulnerable in situations of need which are distant from the specific relationship with the focal subject, and c) outsiders, such as supervisors and bosses, whose relationship with the focal subject is very dependent on their role (García, Martínez \& Albar 2002).

Traditionally, the impact of social support upon job stress in nursing staff has been analyzed according to the help coming from coworkers and supervisors. Bakker et al. (2000) found that supervisors buffered the negative effects of the job demands on HNS. In this same direction, Schmieder \& Smith (1996), Kirmeyer \& Dougherty (1988) showed how high supervisor support levels buffered the negative effects of the job demands and decreased the feelings of emotional exhaustion.

However, some studies have called attention to the advantages of incorporating close families and friends into the studies (Peeters \& Le Blanc 2001, Tyler \& Cusway 1995). The little attention paid to social support coming from kin in the research which analyzes the prevention of emotional exhaustion among HNS contrasts with the synergic capacity that they have in order to be effective in different situations of need, especial- ly among women, the predominant gender among HNS, for which they represent the most significant segment of the network in terms of social support (Barrera 2000). Consequently, it is advantageous to carry out studies which analyze the role that family and friends, together with co-workers and supervisors, have on coping with job stress and the prevention of emotional exhaustion, explaining both the possible direct effects of each of these sources and their possible interactions with the stress.

Goals of Study. The direct and buffering effect of the availability of different social support sources in the prevention of emotional exhaustion among HNS in the south of Spain will be explored. First, the direct relationship between availability of support coming from family and close friends ( $\mathrm{kin}$ ), co-workers (insiders) and the supervisor (outsiders) and job stress and emotional exhaustion will be examined. Afterwards, we will explore the buffering effect of support sources on job stress, observing if the HNS with high stress scores and less emotional exhaustion are those who have each one of the support sources more available, hoping to find an effect of interaction between these and stress.

\section{Method}

\section{Sample}

210 nurses from the Virgen Macarena University Hospital in the city of Seville (Spain) participated. They were selected in the different health care units by means of a systematic random process, through staff lists provided by the Nursing Department. 20 of those selected who were on leave during the study were substituted by the 
next on the list. The average age of the subjects was $41.7(\mathrm{DT}=6.89)$ and $85.6 \%$ were women. $72.9 \%$ had rotating shifts (morning, swing, and graveyard). The average time of professional experience was 18.22 years $(\mathrm{DT}=6.19)$.

\section{Instruments}

Register of Demographic Variables. It contains those variables which in the literature are shown as related to job stress and emotional exhaustion (age, gender, number children and years of professional experience).

Job Stress. It was assessed with the Nursing Stress Scale (Gray-Toff \& Anderson 1981), validated in Spain by Escriba, Mas \& Cárdenas, (1999). It involves 33 items, which describe different potentially stressful situations at work performed by the nursing group at the hospital setting. Each item is scored according to the frequency with which these situations are assessed as stressful, from (0) never, (1) sometimes, (2) frequently, and (3) very frequently. The alpha coefficient of the scale was .91.

Emotional Exhaustion: It was evaluated with the corresponding sub-scale of the Maslach Burnout Inventory (Seisdedos 1997), using the Spanish version drawn up from the original edition of 1986 . It consists of 9 headings to which the interviewee had to respond, according to the frequency of the expressed feelings, from (0) never to (6) always. The alpha coefficient obtained was .91 .

Social Support. To evaluate the availability of social support, the Multidimensional Social Support Scale of Winefield, Winefield \& Tiggemann (1992) was adapted. This scale values the availability of support behaviors on a scale which ranges from (0) never to (3) always, on three sub-scales corresponding to three support sources, family and close friends ( $k i n)$, co-workers (insiders), and supervisor or person of authority (outsiders).

The translation and retro-translation was performed by experts in both languages and was validated in a sample of $150 \mathrm{HNS}$. The factorial structure revealed three factors, which explained $50.34 \%$ of the total variance of the scores. The first contained items referring to the availability of supervisor support and obtained an alpha coefficient of .92; the second, those corresponding to the support from family and close friends (Cronbach's alpha $=.90)$, and the third, those corresponding to the support from co-workers (Cronbach's alpha $=.88$ ). The total scale obtained a high internal consistency (Cronbach's alpha $=.91$ ). To find the test-retest reliability, the scale was re-administered to a random sample of 60 nurses in an interval of three months, obtaining the following alpha coefficients: $.85, .90$ and .89 , for family and close friends, supervisor and co-workers, respectively.

Given the suitability which the psychometric properties presented, it was administered to the participants of our study. In a factorial analysis applied to our data, we confirmed that each sub-scale contained a factor. The one which included family and close friends obtained an alpha of .88, that of co-workers .91, and that of supervisors .90 . The total scale obtained an alpha $=.90$.

\section{Procedure}

250 nurses were given envelopes, which contained the instruments described above. Participants were informed about the aims of the study and they were told that, once 
finished, they were to return them to the hospital research unit. They were told that participation would be voluntary and the answers would be strictly anonymous to avoid the possible effect of social desirability. Most envelopes were returned (98\%), but only 210 subjects representing $84 \%$ of the total could be used for the study, having to disqualify the rest for containing a high percentage of unanswered items.

\section{Results}

The data was analyzed using the statistics package SPSS 10.0. The analysis strategy included several steps. In the first place, once confirmed that our variables followed a normal distribution, a descriptive analysis of the data and the relationships among the studied variables was performed using Pearson's correlation coefficients. Table I presents the results of the correlation analysis, which reflects 16 statistically significant relationships, 7 of them having a value of $p$ $<0.01$.
As can be seen in Table I, the score of job stress is the variable which obtains the highest correlation with the emotional exhaustion factor $(\mathrm{r}=.34, \mathrm{p}<0.01)$, followed by the availability of co-worker support ( $\mathrm{r}=$ $.30, \mathrm{p}<0.01)$. Of the social-demographic variables, age, years of professional experience and number of children appear negatively related to emotional burnout ( $\mathrm{r}=-.19$; $\mathrm{r}=-.15 ; \mathrm{r}=-.16, \mathrm{p}<0.05)$. To test our predictions, a hierarchical multiple regression analysis for the emotional exhaustion dimension factor was carried out. To check the suitability of the analysis, absence of multiccollinearity was tested. The independent variables were introduced using the stepwise method (Aiken \& West 1991). To control the possible confusing effect, the first variable introduced was years of professional experience. Then stress was incorporated followed by availability of support sources. In a fourth step, the interactions of the variables of availability of support of the three sources and stress were introduced. Previously, the predictor variables were centered. In Table II, the obtained results are presented.

Table I

Descriptive statistics for and correlation between the key study variables (list wise). $\mathrm{N}=210$

\begin{tabular}{lccccccccccc} 
& $\mathrm{M}$ & $\mathrm{SD}$ & $\mathrm{A}$ & $\mathrm{CH}$ & $\mathrm{PE}$ & $\mathrm{G}$ & $\mathrm{EE}$ & $\mathrm{ST}$ & $\mathrm{KSA}$ & ISA & OSA \\
\hline $\mathrm{A}$ & 41.72 & 6.91 & 1 & .05 & $.86^{* *}$ & .11 & $-.19^{*}$ & $-.28^{* *}$ & $-.22^{* *}$ & -.09 & -.06 \\
$\mathrm{CH}$ & 1.54 & 1.26 & & 1 & .12 & .04 & $-.15^{*}$ & .01 & .02 & .00 & $-.14^{*}$ \\
$\mathrm{PE}$ & 18.22 & 6.19 & & & 1 & .12 & $-.16^{*}$ & $-.16^{*}$ & $-.14^{*}$ & -.03 & .01 \\
$\mathrm{G}$ & -- & - & & & & 1 & -.10 & -.00 & .05 & .05 & .36 \\
$\mathrm{EE}$ & 38.38 & 14.78 & & & & & 1 & $.34 * *$ & $-.20^{*}$ & $30^{* *}$ & $-.28^{*}$ \\
ST & 13.47 & 4.16 & & & & & & 1 & -.07 & -.07 & $-.15^{*}$ \\
KSA & 8.69 & 3.58 & & & & & & & 1 & $.35^{* *}$ & .09 \\
ISA & 5.90 & 3.87 & & & & & & & & 1 & $.29 * *$ \\
OSA & 15.72 & 6.57 & & & & & & & & & 1 \\
\hline
\end{tabular}

$\mathrm{A}=$ Age $; \mathrm{CH}=$ Children; $\mathrm{PE}=$ Professional Experience; $\mathrm{G}=$ Gender; $\mathrm{EE}=$ Emotional Exhaustions; $\mathrm{ST}=$ Stress; KSA = Kin (Close Family \& Friends) Support Availability; ISA = Insiders (Co-workers) Support Availability; OSA = Outsiders (Supervisor) Support Availability

$* \mathrm{p}<.05$

$* * \mathrm{p}<.01$ 
Table II

Hierarchical multiple regression analysis on emotional exhaustion (step wise). $\mathrm{N}=210$

\begin{tabular}{|c|c|c|}
\hline & Em & Exhaustion \\
\hline & B & $\mathrm{R}^{2}$ Change \\
\hline Step $1^{\text {st }}$ & & $.074 * *$ \\
\hline Professional Experience & $-.19 * *$ & \\
\hline Step $2^{\text {nd }}$ & & \\
\hline Stress & & $.078 * *$ \\
\hline & $.28 * *$ & \\
\hline Step $3^{\text {rd }}$ & & $.180 * * *$ \\
\hline Kin Support Availability (KSA) & $-.33 * *$ & \\
\hline Insiders Support Availability (ISA) & $.44 * *$ & \\
\hline Outsiders Support Availability (OSA) & $-.39 * *$ & \\
\hline Step $4^{\text {th }}$ & & $.052 *$ \\
\hline KSA x Stress & $.27 *$ & \\
\hline ISA x Stress & .04 & \\
\hline OSA x Stress & $.35^{*}$ & \\
\hline Total R-squared & 34.4 & \\
\hline F (Final model) & $9.43 * *$ & \\
\hline
\end{tabular}

It may be observed that significant main effects of stress and of the availability of support from the three sources and the results of the interactions confirm the predictions concerning the buffering effect of the availability of kin and outsider support. These significant interaction effects are graphically represented in Figure 1 and 2 following the method recommended by Aiken \& West (1991). Values of the moderator variables were established with a typical deviation below and above the average. Simple regression lines were generated to insert these values into the regression equation. As can be seen in the Figure 1, at low levels of stress there is hardly any difference in levels of emotional exhaustion between nurses who report high levels of availability kin support and those who report low levels. But, the situation is different when the stress is increasing. In this case, emotional exhaustion rises only among nurses with low scores in kin support availability. In addition, Figure 2 shows that at low levels of stress there is hardly any difference in levels of emotional exhaustion between nurses who report high levels of supervisor support availability and those who report low levels. However, the situation changes when the stress level rises, with an notable increase in emotional exhaustion in those subjects with low levels of supervisor support.

\section{Discussion}

The aim of this study was to explore the direct and buffering effect of three sources of social support on the emotional exhaus- 


\section{$\rightarrow$ Low Availability $\longrightarrow$ High Availability}

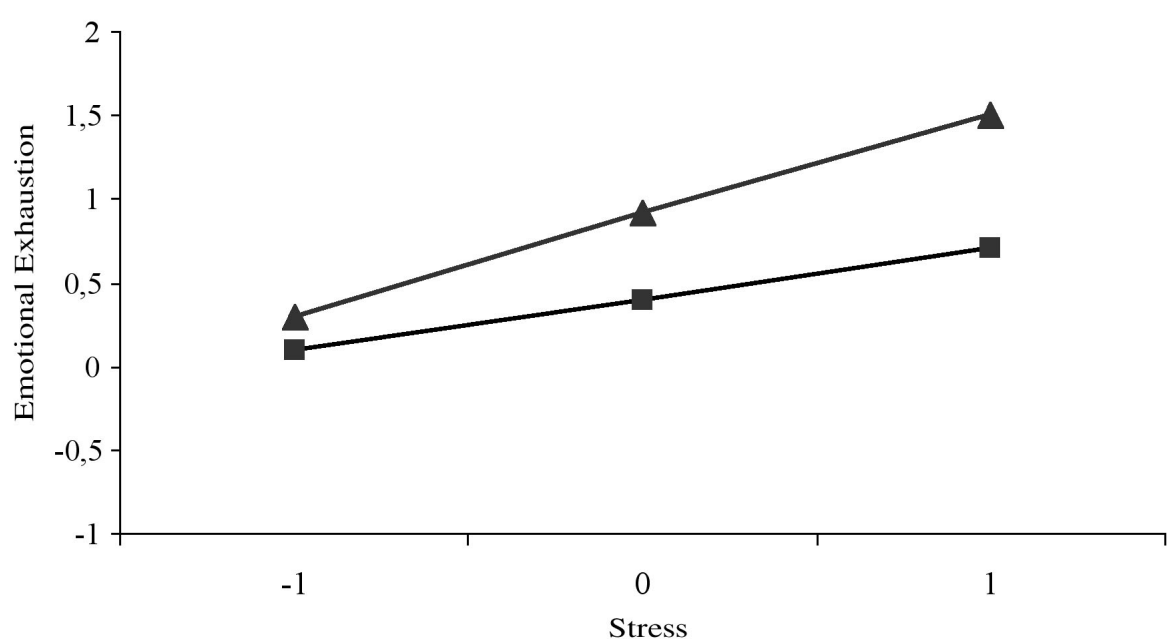

Figure 1. Interaction effect of stress and kin support availability on emotional exhaustion.

\section{$\longrightarrow$ Low Availability $\rightarrow$-High Availability}

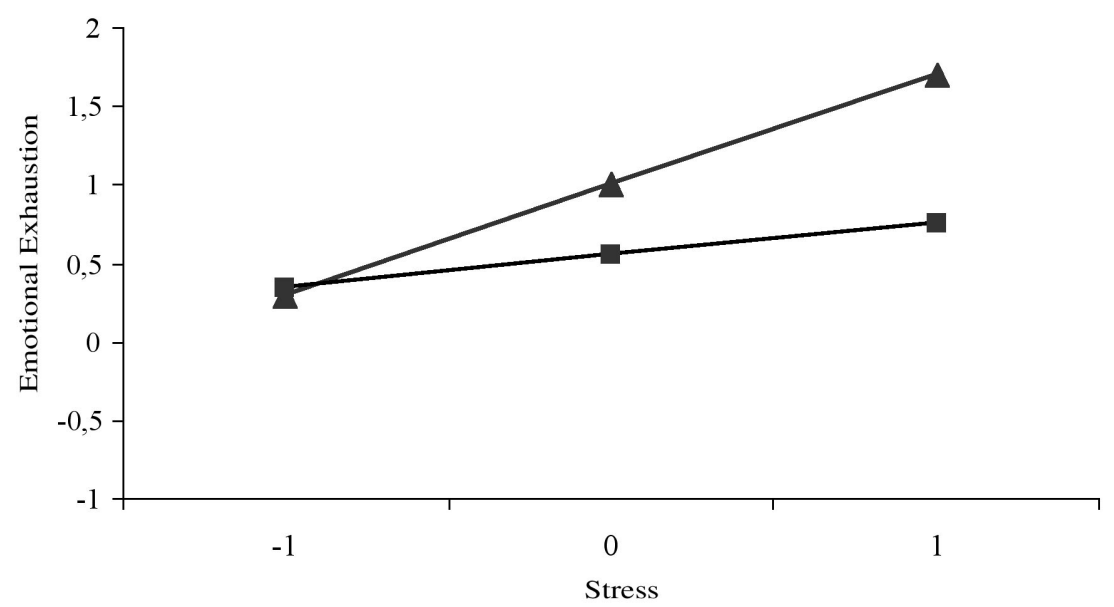

Figure 2. Interaction effect of stress and outsider support availability on emotional exhaustion. 
tion in a sample of HNS. To measure the social support, the Multidimensional Support Scale was used, after adapting it and validating it in a sample of HNS. The high alpha coefficients obtained in the three subscales demonstrate the strong internal consistency and the moderate correlations obtained among them suggest that they are different constructs.

The correlation analysis applied to the variables show that the influence of job stress is a determinant of emotional exhaustion. This finding is in line with theoretical developments, which relate burnout syndrome with job demands (Karasek and Theorell 1990, Lee \& Asforth 1993). Future research must distinguish among types of job demands to differentiate their influence on emotional exhaustion. This result is confirmed in the multivariant analysis, where we also observe the main effect of the different sources of support. The positive relationship found between co-worker support and emotional exhaustion may be interpreted based on the mobilization model of social support (Barrera 2000), which explains how the co-workers are perceived as an effective source of support when the subject is emotionally exhausted. By contrast, in agreement with other studies, negative relationships found in the other two sources, close families and friends and supervisor, suggest that these ties may form an important resource to prevent emotional exhaustion (Bakker et al. 2000, Munro, Rodwell \& Hardin 1998).

Regarding the buffering effect of social support, the results obtained respond to some of the predictions which we formulated. As shown by Figure 1, in agreement with the results obtained in other studies, we find empirical evidence for an interaction between job stress and availability of close family and friends support, indicat- ing that the experience of stress produces less emotional exhaustion in professionals with high availability of support coming from this source (Greenglass et al. 1994). Moreover, our prediction about the buffering effect of the availability of supervisor support has been confirmed, as shown in Figure 2. This result is in line with that obtained by Bakker et al. (2000), who observed that the supervisors could have a buffering effect on job stress if they maintained a leadership style aimed at providing guidance and advice to solve them.

\section{Limitations of the Study}

Our study has limitations that should be taken into account when directing future studies. First, the level of response which we obtained in the questionnaires may slant the level of emotional exhaustion found, since it may be that the HNS with higher levels of emotional exhaustion find themselves among those who refused to answer or who had to be substituted because they were on leave. In order to analyze the role of social support in the burnout syndrome, having considered only one of its dimensions is another limitation. Although it has been suggested that emotional exhaustion reflects the most important aspect of burnout (Maslach Shaufeli \& Leiter 2001), it is beneficial to assess the influence of social support on the other dimensions. Cordes et al. (1993) show that these appear later in the burnout process, so it is probably more difficult to assess them in active professionals and, as a result, longitudinal studies must be carried out, not limited to the active population. In addition, this type of design would the establishment of causal relationships. 
Other limitations of our study come from the sample selected. For one thing, its reduced size has prevented the assessment of the influence of other variables relevant to social support, such as sufficiency and the kind of aid provided by the sources. In addition, the fact that only one hospital has been studied has not allowed historical and contextual variables to be controlled, which may have slanted the results. Consequently, given that the analysis of the relationships between job stressors, social support and emotional burnout requires the use of batteries with multiple instruments, it is necessary to use samples whose size and diversity allow appropriate analyses to be carried out, ensuring statistical strength and stability in the results.

\section{Implications for Future Research and Interventions}

In line with proposals by Sarason, Sarason and Pierce (1994), our results suggest the importance of a deeper study of the influence of social support on the process of job stress and the differentiating role of the different support sources in the process of confronting job stress and preventing emotional exhaustion, thus preventing burnout syndrome.

Moreover, the interconnection which we have found between the working world and other aspects of professionals' lives suggests the need to carry out future studies based on an ecological perspective. This perspective provides in-depth analysis of how perceptive factors and objectives related to family, organizational, community and cultural contexts interact to have an impact on professionals' psychological output (García et al. 2002).
Furthermore, as shown by Cox, Kuk \& Leiter (1993), if we understand stress as the result of person-environment transaction, and social support as the set of resources which complete the personal ones, it is necessary for future studies to include variables related to personal features. Currently, it has become important to analyze this type of resource in terms of psychological empowerment in the workplace, understood as the set of features, which enable professionals to adequately and effectively perform their jobs. These features are meaning, or an adjustment between the requirements of the job tasks and the worker's own values, beliefs, and behaviors; competence as the belief that one possesses the skills and abilities necessary to perform a job or task well; self-determination as the feeling of having control over one's own work; and impact as the belief that one has a significant influence over the strategies and outcomes at work (Spreitzer 2000).

Our results also have practical implications. They suggest the need to promote aid search styles for HNS based on social support sources, by means of : a) promoting leadership styles among supervisors based on smooth communication with HNS which provides specific help, b) promoting teamwork based on self-help and on collective values at the workplace and c) facilitating cohesion in the family group, helping HNS to acquire a critical consciousness concerning the need to adapt their role in the family with that at work, making the family routine a source of support and well-being (e.g. promoting healthy work shifts).

In summary, our results have implications for future studies which deal both with the influence of social support on coping with job stress and with optimizing job health and quality of life among hospi- 
tal nursing professionals. Among other aspects, they suggest carrying out interventions which promote open communication between supervisors and professionals. In addition, they suggest carrying out interventions designed to join and adapt working life with family life, as well as promoting aid search styles based on social support resources.

\section{References}

Aiken LS, West SG. Multiple regression: Testing and interpreting interactions. Newbury Park, California: SAGE; 1991.

Bakker AB, Killmer CH, Siegriest J, Shaufeli WB. Effort - reward imbalance and burnout among nurses. J Adv Nurs 2000; 31: 884-891.

Barrera M. Social support research in community psychology. In J. Rappaport \& E. Seidman (Eds). Handbook of community psychology. New York: Kluwer Academic. 2000.

Chapell NL, Novak M. The role of support in alleviating stress among nursing. Gerontologist 1992; 32(3): 351-359.

Cordes CL, Dougherty TW. A review and an integration of research on job burnout. Acad Manage Rev 1993; 18: 621-656.

Cox T, Kuk G, Leiter M. Burnout, health, work stress, and organizational healthiness. In: Shaufeli WB, Maslach C, Marek T, eds. Professional burnout: Recent developments in theory and research. London: Taylor \& Francis 1993; 177193.

Eisenberger R, Fasolo P, Davis-Lamastro V. Perceived organizational support and employee diligence, commitment, and innovation. J Appl Psicol 1990; 75: 51-59.

Escriba V, Mas R, Cárdenas M, Pérez S. Validación de la escala de estresores laborales en personal de enfermería: "The nursing stress scale". Gac Sanit 1999; 13(3): 191-200.

García M, Martínez M, Albar MJ. La elección de fuentes de apoyo social entre inmigrantes. Psicothema 2002; 14(2): 369-374.

Gray-Toft P, Anderson J. The Nursing Stress Scale: development of an instrument. J Behav Assess 1981; 3: $11-23$.

Greenglass ER, Fiksenbaum L, Burke RJ. The relationship between social support and burnout over time in teachers. J Soc Behav Pers 1994; 9: 219-230.
Karasek RA, Teorell T. Healthy work: stress, productivity and the reconstruction of working life. New York: Basic Books; 1990.

Kaufmann GM, Beehr TA. Interaction between job stressors and social support: some counter intuitive results. $J$ Appl Psychol1986; 71: 522-526.

Kirmeyer SL, Douhherty TW. Work load, tension and coping: Moderating effects of supervisor support. Personnel Psychol 1988; 41: 125-139.

Lazarus RS. Psychological stress in workplace. In: Perrewe PL, eds. Handbook on job stress. Corte Madera (California): Select Press 1991; 1-13.

Lee RT, Asforth BE. A longitudinal study of burnout among supervisors and managers: comparison between the Leiter \& Maslach (1988) and Golembiewski et al (1986) models. Organ Behav Hum Decis Process 1993; 54: 369398.

Leiter MP. Burnout as a developmental process: Consideration of models. In: Shaufeli WB, Maslach C, Marek T, eds. Professional burnout: recent developments in theory and research. London: Taylor \& Francis 1993; 237-250.

Maslach C, Leiter MP.The truth about burnout: How organizations cause personal stress and what to do about it. San Francisco: Josey - Bass; 1997.

Maslach C, Shaufeli B, Leiter MP. Job Burnout. Annu Rev Psychol 2000; 52: 397-422.

Munro L, Rodwell J, Harding L. Assessing occupational stress in psychiatric nurses using the full job strain model: The value of social support to nurses. Int J Nurs Stud 1998; 35: 339-345.

Peeters MCW, Le Blanc P. Towards a match between job demands and sources of social support: A study among oncology care providers. Eur J Work Organ Psychol 2001; 10(1): 53-72

Sarason B, Duck S. Personal Relationship: Implications for Clinical and Community Psychology. Chichester (England): John Wiley \& Sons Ltd, 2001.

Sarason IG, Sarason BR, Pierce GR. Relationship-specific social support: Toward a model for the analysis of social interaction. In: Burleson BR, Albrecht TL, Sarason IG, eds. Communication of social support: Messages, interaction, relationship and community. Thousand Oaks, (California): Sage Publications; 1994.

Schmieder RA, Smith CS. Moderating effects of social support in shift working nurses. Work Stress 1996; 10: 128140.

Seisdedos, N. MBI Inventario "Burnout" de Maslach: Manual. Madrid: TEA; 1997. 
Shaefer JA, Moos RM. Work stressors in health care: Contexts and outcomes. J Community Appl Soc Psychol 1993; 3(4): 235-259.

Shaufeli WB, Leiter MP, Maslach C, Jackson SE. The Maslach Burnout Inventory : General Survey. In: Maslach C, Jackson SE, Leiter MP, eds. Burnout Inventory Manual. Palo Alto (California): Consulting Psychologist Press; 1996.

Spreitzer GM. Social structural characteristics of psychological empowerment. Acad Manage Jl 2000; 38(2): 483504.

Tyler PA, Cusway D. Stress in nurses: The effects of coping and social support. Stress Med 1995; 11: 243-251.
Winefield HR, Winefield AH, Tiggemann M. Social Support and Psychological Well-being in Young Adults: The Multi- Dimensional Support Scale. J Pers Assess 1992; 58(1): 198-210.

Address of correspondence:

María Jesús Albar Marín

Hospital Universitario Virgen Macarena.

Unidad de Investigación.

Avenida Dr. Fedriani, n 3. 41073 Sevilla.

E-mail: mariaj.albar.sspa@juntadeandalucia.es

SPAIN 